\title{
Professional recommendations: disclosing facts and values
}

Françoise Baylis and Jocelyn Downie Dalhousie University, Halifax, Nova Scotia, Canada

\begin{abstract}
It is not unusual for patients and their families, when confronted with difficult medical choices, to ask their physicians for advice. This paper outlines the shades of meaning of two questions frequently put to physicians: "What should I do?" and "What would you do?" It is argued that these are not questions about objective matters of fact. Hence, any response to such questions requires an understanding, appreciation, and disclosure of the personal context and values that inform the recommendation. A framework for considering and articulating a response to these questions is suggested, using as a heuristic the phrasing "If I were you.../If it were me..."

(Fournal of Medical Ethics 2001;27:20-24)
\end{abstract}

Keywords: Professional-patient relations; informed consent; truth disclosure; ethics, medical

'What should we do?/What would you do?' Joanna, a woman with spina bifida, is nineteen weeks pregnant. She and her husband Paul have just learned that Joanna is carrying a fetus with spina bifida. They ask their physician, Dr Ricardo, "What should we do?" Dr Ricardo evades the question by responding, "I can't tell you that," and immediately shifts the discussion to procedural matters by saying: "If you decide to terminate the pregnancy, I should book you in as quickly as possible." A day or so later, still agonising over the decision about whether to continue the pregnancy, Paul returns to see Dr Ricardo and asks her: "What would you do?" Dr Ricardo again evades the question and focuses on procedural matters. ${ }^{1}$

The questions asked of Dr Ricardo are not unusual. Patients and members of their families faced with difficult health care decisions for themselves or their loved ones often will approach their physicians with apparent requests for advice and guidance. How their physicians understand and respond to such requests is the focus of this paper.

For some, Dr Ricardo's responses are ethically appropriate. The underlying reasoning is as follows. Questions such as "What should we do?" and "What would you do?" are requests for a professional recommendation. Professional recommendations, not unlike personal recommendations, are necessarily value-laden as the information that physicians choose to disclose to patients and the manner in which they do so is necessarily informed by the values they hold (many of which may be the result of professional socialisation). To avoid imposing their values on their patients, physicians should refrain from offering professional recommendations. On this view, by saying "I can't tell you that," Dr Ricardo acts in an ethically appropriate manner that is consistent with an ethos of value neutrality and the practice of non-directive counselling in the area of reproductive choice. She thereby avoids imposing her values (and treatment goals) on her patients.

For others, however, Dr Ricardo's responses are ethically inappropriate. Here, the guiding assumption is that physicians have a moral obligation to provide patients with a professional recommendation as part of the informed choice process. According to Tom Beauchamp and Jim Childress, for example:

"Professionals are obligated to disclose a core set of information, including (1) those facts or descriptions that patients or subjects usually consider material in deciding whether to refuse or consent to the proposed intervention or research, (2) information the professional believes is material, (3) the professional's recommendation, (4) the purpose of seeking consent and, (5) the nature and limits of consent as an act of authorization." ${ }^{2}$ (Emphasis added)

Consider also the following classic statement by Franz Ingelfinger:

"The physician should recommend a specific course of action. He [sic] must take the responsibility, not shift it onto the shoulders of the patient. The patient may then refuse the recommendation, which is perfectly acceptable, but the physician who would not use his training and experience to recommend the specific action to a patient ... does not warrant the somewhat tarnished but still distinguished title of doctor." ${ }^{3}$

On this alternative view, in side-stepping Joanna and Paul's questions and failing to provide them with material information - information that would reasonably be expected to affect their decision making since they expressly requested the information-Dr Ricardo abdicates her moral responsibility to her patients under the guise of respecting their autonomy. Others would go further still and suggest that in most physician-patient encounters, the failure to offer a professional recommendation regarding treatment options "would probably be seen as grounds for a malpractice charge due to culpable negligence". ${ }^{4}$ 
As regards our own view, we doubt the possibility of value neutrality and we do not believe that Dr Ricardo's responses are ethically appropriate. We are of the view that providing patients and families with a professional recommendation is an important part of the informed choice process, especially when the patient specifically asks for such information, thereby clearly indicating that she considers this information material in evaluating her treatment options. The physician has an obligation to disclose not only information that she and her colleagues consider material (the professional standard of disclosure), or information that reasonable patients generally consider material (the patient-centred standard for disclosure), but also and more specifically, information that the patient indicates is material, perhaps by the questions she asks. More precisely, when specific questions are asked of physicians, they owe their patients either direct and responsive answers or an explanation of why they cannot or should not answer the questions put to them. It follows that when patients request a professional recommendation, an opinion or an explanation should be forthcoming. Dr Ricardo's failure to answer the questions "What should I do?" and "What would you do?" through evasion, or unexplained refusal is unsatisfactory.

Because we are committed to the view that physicians have an obligation to provide their patients with information that their patients consider material for decision making purposes (and this may include a professional recommendation), we are concerned by the apparent failure both in the literature and in practice to distinguish between morally acceptable recommendations that enhance decision making, and morally unacceptable recommendations that actually diminish patient autonomy. The goal of this paper is to elucidate this distinction.

\section{Morally unacceptable professional recommendations}

Not all possible responses to a request for a professional recommendation are ethically appropriate and, indeed, some are particularly inappropriate. For instance, prefacing one's answer to such questions as "What should I do" or "What would you do" with "In my professional opinion, ..." potentially undermines voluntariness. To state the obvious, this prefatory clause potentially hinders voluntariness because it plays on the inherent power imbalance in the physician-patient-family relationship. Moreover, this phrase, which is analogous to Robert Veatch's "Speaking-as-aphysician", 5 is potentially misleading because it cloaks an answer that necessarily includes subjective elements based on personal and/or professional values in the authority and apparent neutrality of an objective answer based solely on medical knowledge, training, and experience. A physician's professional recommendations are neither valuefree nor value-neutral; rather, they are "the product of an intermingling of subjective and objective elements". ${ }^{6}$ In differing ratios, they are informed by factual-informational details and value judgments shaped by political, social, and personal circumstances, desires, interests, and prejudices. As such, recommendations are inextricably objective and subjective, and "fall along a continuum, where some are more purely objective [for example, 'you are pregnant and need to alter your diet']; others manifest a greater interplay of subjectivity and objectivity [for example, 'a caesarean section is medically indicated']; others again are more purely subjective [for example, 'you should have an abortion because the fetus has a genetic defect']."

\section{Inadequate disclosure}

In our view, answering such questions as "What should I do?" or "What would you do?" without revealing both the objective and subjective elements that inform the answer constitutes inadequate disclosure. A widely accepted requirement of adequate disclosure is the provision of relevant factual-informational details. It is understood that disclosure of such details is imperative if the patient and family are to assess the physician's recommendation and, on this basis, make an informed choice. An equally legitimate requirement of adequate disclosure is the provision of information about the value judgments underlying the recommendation. This requirement is legitimate precisely because recommendations are the product of an intermingling of objective and subjective elements. If the objective elements must be disclosed, as is widely accepted, then for the same reasons, the subjective elements must also be disclosed.

Thus, the physician owes the patient an account of the reasoning underlying her recommendation so that the patient can understand and evaluate the suggested course of action. We agree with Howard Brody that "disclosure is adequate when the physician's basic thinking has been rendered transparent to the patient" ${ }^{8}$ The patient must be told "precisely the grounds on which the physician has made her recommendation". " Unlike Brody, however, we believe that rendering one's reasoning process transparent requires more than a disclosure of informational details (for example, risks, benefits, alternatives). Since the reasoning underlying any recommendation necessarily involves value judgments as well as factual-informational details, and since one cannot presume that physicians and patients share the same values, both factualinformational details and value judgments must be disclosed.

To return to the case under discussion, if Dr Ricardo were to say "I think you should carry this fetus to term" or "I think you should have an abortion" when only factual-informational details have been disclosed (for example, the fetus is afflicted with spina bifida), then clearly her response would be inadequate. Disclosure of the value judgments underlying the recommendation (be they the physician's and/or the patient's values) is necessary for adequate disclosure.

In sum, it is ethically inappropriate to respond to such questions as "What should I do?" or "What 
would you do?", by prefacing any answer with "In my professional opinion,..." (or other authoritybased locutions), or by limiting the answer to a disclosure of the recommendation and the underlying factual-informational details with no effort to expose the personal and/or professional values that have influenced the information communicated. If the patient and family are to make an informed choice, the physician must disclose both the factual-informational details and value judgments that inform the recommendation, insofar as the physician knows them.

\section{Morally acceptable professional recommendations}

When a patient asks "What should I do?" or "What would you do?" the physician first needs to ascertain what is really being asked of her. Does the patient want information, reassurance, guidance, understanding, or empathy? For example, the patient may be asking: "Why did this happen to me?" "What has happened to other patients like me?" "What do you think will happen to me?" "Is there a standard professional response or approach?" Alternatively, the patient may simply be asking for understanding. For example, in discussing a physician-patient exchange about a possible termination of pregnancy because the fetus has a genetic defect, Richard Zaner claims that the patient was not "asking for an act of imaginative identification (for the doctor to become the person facing the situation and try to feel her pain). Nor was she asking him to consider what he would do if he and his wife faced the same situation." ${ }^{10}$ Rather, she was simply asking for understanding. If, however, after entertaining/evaluating various possible interpretations of the question, the physician concludes that the patient is indeed asking for advice in the form of a professional recommendation, she must next determine which perspective (ie whose value judgments) should inform her response, assuming there is no compelling reason not to provide a recommendation. That is, is the patient asking "What would you do if you were me?" or "What would you do if it were you?"

\section{'What would you do if you were me?'}

If the patient confirms for the physician that the question she is truly concerned with is "What would you do if you were me?" (ie if you had my medical status along with my personal history and $m y$ values?") the physician may elect to engage in an "act of imaginative identification" and entertain the belief that she is the patient facing the situation. This presumes, however, that in addition to knowing the patient's medical condition, the physician is familiar with the patient's personal context and values and, moreover, is both: i) aware of her own personal and professional values; and ii) able to set these aside when they diverge from the patient's values. Only then would the physician be able to provide a recommendation informed by relevant factual-informational details and an understanding and appreciation of the patient's value considerations. In so doing, however, it is incumbent upon the physician to verify with the patient the accuracy and relative completeness of the personal information. This may be complicated for a number of reasons, as outlined below.

Sometimes, the patient is ignorant of, or mistaken with regard to, her beliefs and values. ${ }^{11}$ In the case of patient error, the physician may elect to challenge the patient's stated value(s) in an attempt to persuade her to reconsider her value(s) in light of the factual-informational details and alternative value judgments.

Alternatively, the patient may hold conflicting values. In some cases this may be irrelevant to the physician's recommendation, as when conflicting values support the same course of action. In other cases, however, the patient's conflicting values may support mutually exclusive courses of action. In such cases, the best the physician can do is help the patient understand which of her values support which course(s) of action.

As well, the patient's values may be in flux. Inevitably, our values are revised as we face new situations, experiences, or arguments. Thus, when confronted with new medical information on which to base a personal choice that may have profound social and moral consequences, a patient may reasonably be expected to question or reassess her values and the importance she previously attached to them. In such instances, the physician may be able to help the patient examine her values and assess their importance in light of the new circumstances.

In contrast, in some cases, the physician knows the patient's medical condition but has little or no information about the patient's personal context and values - the patient is a stranger. Levine and others use the term "stranger" to describe the patient with whom the physician has no intimate or enduring relationship. ${ }^{12}$ We use the term "stranger" for the patient whose personal context and values are essentially unknown to the physician. In our view, a patient may have an enduring relationship with a physician without the physician having any meaningful knowledge of the patient's personal context and values. Likewise, it is possible for the physician, solely on the basis of episodic encounters, to have intimate knowledge of the patient's beliefs and values.

If the patient is a stranger, for example in an emergency setting or on an initial scheduled visit, it is important that the physician not make assumptions about the patient's interests and values. Rather, the physician must attempt to elicit the missing information. It is widely accepted that a physician is not at liberty to refuse to gather factual-informational details about a patient's condition. Similarly, in our view, the physician is not free to refuse to gather information about the patient's value judgments when this information is relevant to the recommendation the physician may ultimately be called upon to make. 
If the physician is successful in her efforts to gain an understanding of the patient's values, then she can offer a recommendation in response to a request centred on patient values. In many instances, however, it may be impossible to elicit the relevant personal information. The patient may be unwilling or unable to share such information due to a lack of time and intimate surroundings (as in emergency situations), a desire for privacy, fear of being judged, a lack of relevant self knowledge, a certain ambivalence on key matters, or mental incapacity. Second, the physician may be unskilled in eliciting values information. In either case, the physician then has but two options. She can decline to answer the question on the grounds that relevant information is missing, or she can offer to answer a different question (for example, "What have other patients done in similar circumstances?")

If the first of these options is chosen, the physician must clearly explain to the patient why she is not answering the question. If the second of these options is chosen, the physician must clearly explain to the patient that the question being answered is different from the question that was asked. This explanation is particularly important when the difference between the question asked and the question answered is subtle but significant (such as the difference between "What would you do if you were me?" where the physician attempts to answer the question from the patient's perspective, and "What would you do if it were you?" where the response is informed by the physician's personal and professional values).

\section{'What would you do if it were you?'}

If the patient who asks "What should I do?" or "What would you do?" confirms for the physician that the question she is truly concerned with is "What would you do if it were you?" (ie, if you had my medical status but your personal history and your moral framework?") the physician may respond in one of two ways.

If the physician is willing to share information about her context and values (insofar as she is aware of them), then she may do so and answer the question, while carefully explaining how her answer is based not only upon her understanding of the factual-informational details but also upon her personal and professional values. The patient should then be encouraged to think about whether these values are or are not consonant with her own values.

Alternatively, if she is unwilling to share information about her personal context and values, then she may refuse to answer the question because, by answering without sharing, she risks imposing her beliefs and values on the patient - either because the patient ascribes undue authority to the physician's recommendation or responds with undue deference. The authority is undue because although physicians may have special medical knowledge that their patients do not have, they do not, by virtue of being physicians, have special ethical knowledge. As Veatch notes: "the problem is one of generalization of expertise: transference of expertise in technical aspects of a subject to expertise in moral advice". ${ }^{13}$ The deference (ie, "compliance with advice etc of one superior in wisdom or position"14) is undue because physicians as a professional group do not have superior knowledge of value considerations. Moreover, since health care decisions of the sort we are concerned with here rightfully belong to patients and families, physicians are not superior in position.

\section{Dr Ricardo's response}

The apparently straightforward questions "What should I do?" and "What would you do?" are ambiguous; different interpretations of these questions suggest different ethically defensible responses. If the request is for a professional recommendation, the physician's response must include a disclosure of the underlying factualinformational details and value judgments that inform her answer. The value judgments may be those of the patient and/or those of the physician. Accordingly, the physician must consider how well she knows the patient, how well she knows herself, and how much she is willing to share of herself. These factors must be carefully considered before the physician responds "If I were you..." or "If it were me...". ${ }^{15}$

From this discussion it follows that Dr Ricardo's responses to the questions put to her on two separate occasions (first by the couple together and then by the husband alone) are inappropriate. As noted previously, evasion or unexplained refusal does not satisfy the requirements of adequate disclosure for informed choice. When a patient asks a physician for a recommendation, he or she deserves a meaningful answer. If Joanna and Paul were "strangers", and Dr Ricardo was unable to elicit information about their personal context and values or, alternatively, if Dr Ricardo was unwilling to share information about her own values then this should have been discussed. Otherwise, Dr Ricardo should have provided Joanna and Paul with a recommendation based on disclosed factual-informational details and value judgments - such are the requirements of adequate disclosure aimed at free and informed choice for patients and their families.

\section{Acknowledgments}

Helpful comments on earlier drafts of this paper were provided by John Hardwig, Hilde Nelson, Susan Sherwin, and an anonymous reviewer.

Françoise Baylis, PhD, is Associate Professor in the Departments of Bioethics and Philosophy, Faculties of Medicine and Arts and Social Sciences, Dalhousie University, Halifax, Nova Scotia, Canada. Focelyn Downie, SFD, is Director of the Health Law Institute and Assistant Professor in the Faculties of Law and Medicine, Dalhousie University, Halifax, Nova Scotia, Canada. 


\section{References and notes}

This scenario is taken from a vignette produced by the National Film Board of Canada. National Film Board of Canada. Who Should Decide? Discussions in Bioethics (Pyramid Film and Video, 1986). The vignette raises a number of ethical issues; the focus of this paper, however, is solely on the ethical acceptability of Dr Ricardo's response to the questions put to her by her patient(s).

2 Beauchamp T, Childress JF. Principles of biomedical ethics [4th ed]. New York: Oxford University Press, 1994: 147

3 Ingelfinger F. Arrogance. New England fournal of Medicine 1980;303:1509.

4 Caplan AL. Neutrality is not morality: the ethics of genetic counselling. In: Bartels DM, LeRoy BS, Caplan AL, eds. York: alter De Gruyter, 1993: 152.

5 Veatch R. Ethical medicine in a revolutionary age. Hastings Center Report 1972;2:3-6.

6 Code L. What can she know? Feminist theory and the construction of knowledge. Ithaca: Cornell UP, 1991: 30.

7 See reference 6 . More generally, this premise borrows heavily from Code's analysis of knowledge as inextricably subjective and objective.
8 Brody H. Transparency: informed consent in primary care. Hastings Center Report 1989;19:5-7.

9 See reference 8: 8.

10 Zaner R. Experience and moral life: a phenomenological approach to bioethics. In: DuBose ER, Hamel R, O'Connell L, eds. A matter of principles? Ferment in US bioethics. Valley Forge, Penn: Trinity Press International, 1994: 219.

11 Brock DW. The ideal of shared decision making between physicians and patients. Kennedy Institute of Ethics fournal 1991;1: 28-47.

12 Levine R. Medical ethics and personal doctors: conflicts between what we teach and what we want. American fournal of Law and Medicine 1987;13:351-64.

13 See reference 5: 6 .

14 Fowler HW, Fowler FG, eds. The concise Oxford dictionary. Oxford: Clarendon, 1964: 319

15 It should be emphasised here that the phrasing "If I were you..." "If it were me ..." is not meant to suggest a scripted response to versions of the questions "What should I do?" or "What would you do?" It is only intended as a heuristic to highlight the perspective from which the patient's question is being answered. 